This item was submitted to Loughborough's Research Repository by the author.

Items in Figshare are protected by copyright, with all rights reserved, unless otherwise indicated.

\title{
An analysis of specialist and non-specialist user requirements for geographic climate change information
}

PLEASE CITE THE PUBLISHED VERSION

http://dx.doi.org/10.1016/j.apergo.2013.03.029

PUBLISHER

(C) Elsevier Ltd and The Ergonomics Society

VERSION

AM (Accepted Manuscript)

LICENCE

CC BY-NC-ND 4.0

\section{REPOSITORY RECORD}

Maguire, Martin. 2019. "An Analysis of Specialist and Non-specialist User Requirements for Geographic Climate Change Information”. figshare. https://hdl.handle.net/2134/12305. 
This item was submitted to Loughborough's Institutional Repository (https://dspace.lboro.ac.uk/) by the author and is made available under the following Creative Commons Licence conditions.

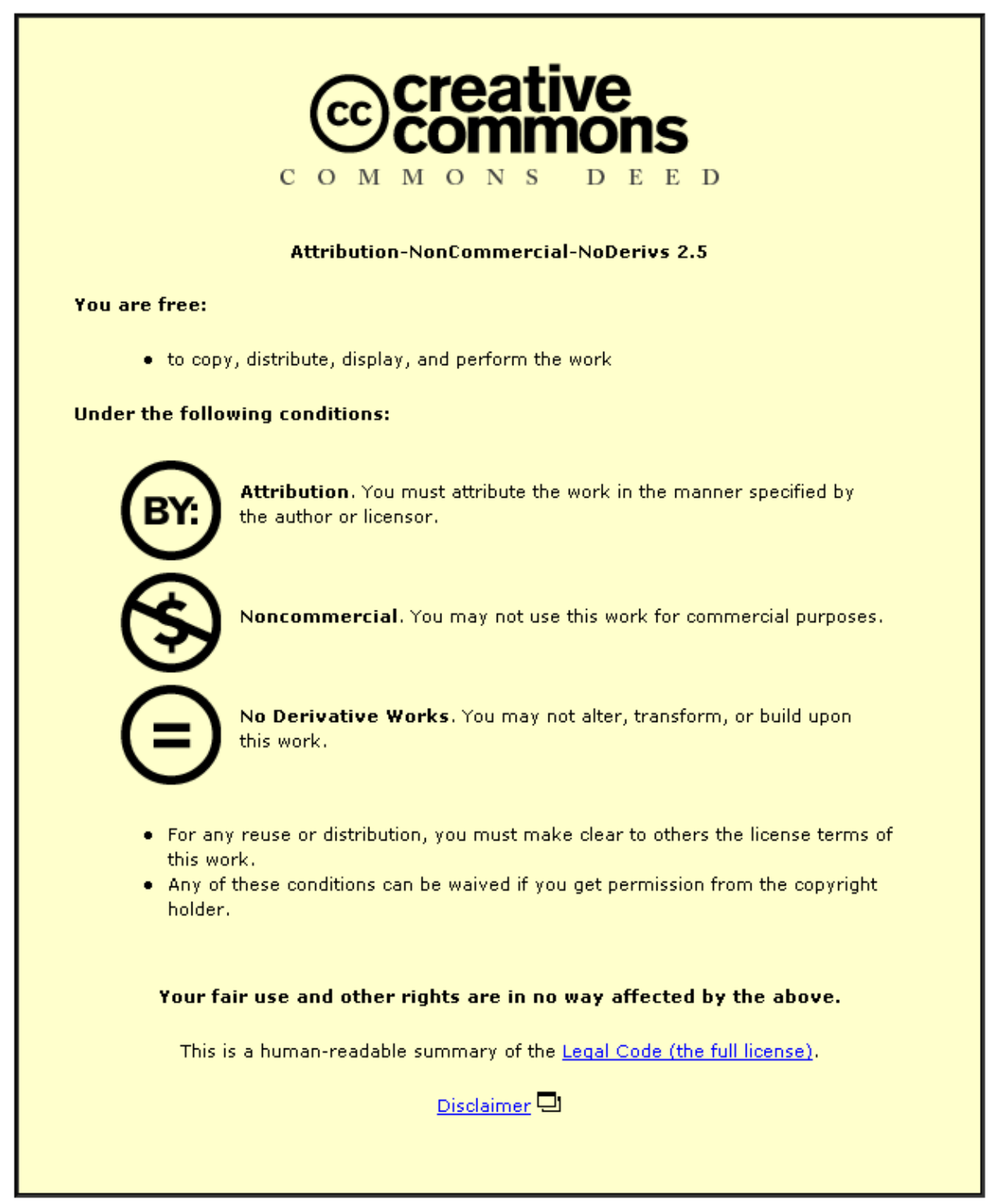

For the full text of this licence, please go to: http://creativecommons.org/licenses/by-nc-nd/2.5/ 


\title{
An analysis of specialist and non-specialist user requirements for geographic climate change information
}

\author{
Martin C. Maguire \\ Loughborough Design School, Loughborough University, \\ Ashby Road, Loughborough, Leicestershire, LE11 3TU, UK \\ m.c.maguire@lboro.ac.uk
}

\begin{abstract}
The EU EuroClim project developed a system to monitor and record climate change indicator data based on satellite observations of snow cover, sea ice and glaciers in Northern Europe and the Arctic. It also contained projection data for temperature, rainfall and average wind speed for Europe. These were all stored as data sets in a GIS database for users to download. The process of gathering requirements for a user population including scientists, researchers, policy makers, educationalists and the general public is described. Using an iterative design methodology, a user survey was administered to obtain initial feedback on the system concept followed by panel sessions where users were presented with the system concept and a demonstrator to interact with it. The requirements of both specialist and nonspecialist users is summarised together with strategies for the effective communication of geographic climate change information.
\end{abstract}

Keywords: climate change; geographic information; graphical representation; user needs

\section{Introduction}

Climate change can affect the living conditions of people worldwide. Dramatic changes may occur with the weather becoming more extreme, along with greater frequency of flooding, droughts and hurricanes. It is not known whether northern Europe will experience regional cooling or warming in a future warmer world. A report by the UK Climate Impacts Programme (Chapman, 2002) states that summer temperatures in the UK, for instance, could regularly reach $40^{\circ} \mathrm{C}\left(104^{\circ} \mathrm{F}\right)$ by the year 2080 as global warming appears to gather pace. Prince Charles called climate change the "greatest challenge to face man" (Mukherjee, 2005) while it is also observed that sea-ice is retreating dramatically in the autumn as well as the summer months (Amos, 2013). The potential effects of climate change are brought home by powerful images of sea level rise, coastal erosion, drought, displacement of people and changes in the habitat of wildlife. These developments are documented officially by the Intergovernmental Panel on Climate Change (http://www.ipcc.ch).

To support climate change research, there is a need for current data from the environment. Satellite monitoring of climate change indicators such as sea ice, snow and glaciers in Northern Europe and the Arctic is one source. This paper presents the results of a user requirements study conducted within the EU EuroClim project (European Climate Change Monitoring and Prediction System). It also includes strategies resulting from the study for the effective communication of GIS (Geographical Information System) climate change data to meet the needs of both specialist and non-specialist users.

Previous work has been conducted on establishing user requirements for climate monitoring systems. Tett et al (2006) noted some key points:

- Climate monitoring needs to be carried out over very long periods so it is important that a system for capturing climate change data is flexible enough to be able to handle data from changing instruments (for example, satellites) and to provide continuity with legacy climate data measurements.

- Stability (repeatability) and accuracy (needed to understand climate processes and changes) are two mandatory requirements for climate monitoring across all satellite missions.

- Traceability in processing the satellite data to create climate data is needed so that any propagation of errors can be traced through the processing train, allowing for an assessment of uncertainty in the resulting climate products.

Bernholdt et al (2005) commented that while data from climate model simulations are of great interest to researchers, policy makers, educators, and others, they require considerable knowledge of all the 
services and resources necessary to make use of the data. They need to know how to access the relevant system account, how the archiving system is organised, how to use metadata for searching, the analysis software for extracting specific subsets, and so on. Due to this complexity, access tends to be restricted to privileged specialists. The goal of the Earth System Grid (ESG) project was to simplify the task of making climate data available to others and provide easier access to that data by presenting it in web page form.

In order to gather valid user requirements, a stakeholder analysis is important to help identify the main categories of user for a potential system (Taylor, 1990). This classification can then form the basis for further research to identify specific user needs. A user survey (Robson, 2011) is a good starting point for this and including both closed and open ended questions so that respondents may express their requirements flexibly and not feeling too restricted by the format. Clear and carefully written questions directed at specific users will further increase response rates and improve validity. This method is commonly followed by face-to-face data gathering with focus groups or interviews (Maguire, 2003; Robson, 2011) using the survey responses to generate more detailed requirements. A widely accepted process for generating user requirements and applying them within system development is 'iterative design', a cyclical methodology of specifying user requirements, developing a system prototype, testing this with users, refining the requirements, modifying the prototype, retesting, etc. (Gould et al, 1991; ISO 9241-210, 2010). This process is intended to ultimately improve the quality and functionality of the system design for the users.

\section{The EuroClim Project}

The aim of the EU EuroClim project (IST-2000-28766) was to develop an advanced climate monitoring and projection system for Europe. Using satellite images at a resolution of $1 \mathrm{~km} / \mathrm{pixel}$, the system was intended to monitor changes in sea ice, land snow and glaciers in the 'cryosphere' (Solberg, 2002, 2005). This includes the Arctic Ocean and high-mountain areas with seasonal snow including Greenland, Svalbard and Scandinavia as shown in Fig. 1.

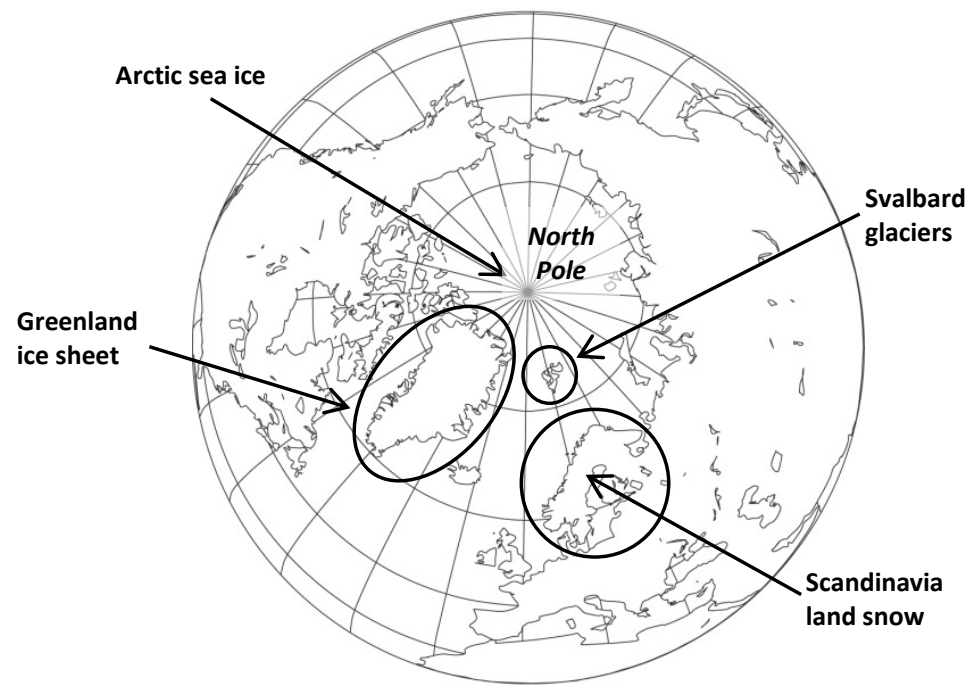

Fig. 1. EuroClim monitoring areas

The project developed a distributed system where climate observations were collected by a consortium of climate research organisations across Europe and integrated into a single database from which users could access climate data products - see examples in Fig. 2. An automated mechanism to acquire, process and store cryospheric data was established. The aim was to create a historical database from 1980 to 2000 and to keep it updated as an on-going process. 

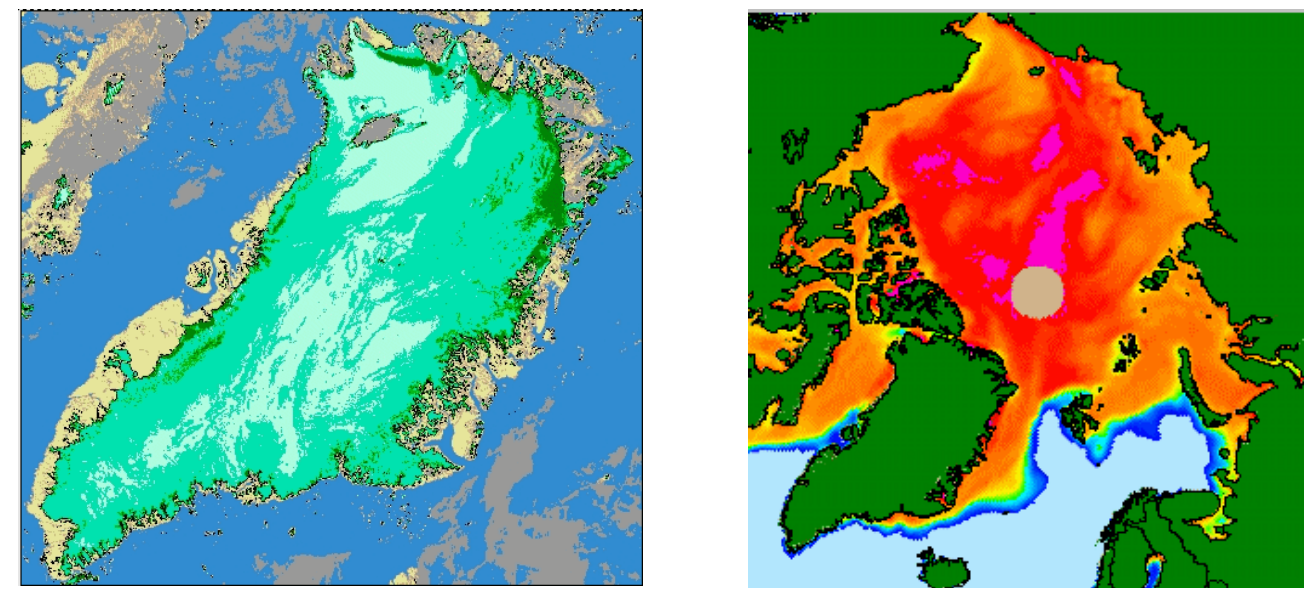

Fig. 2. Sample observed output from EuroClim: (i) Observation of glacier surface area; (ii) Modelled output of sea ice area and concentration

The system also contained output from a climate model to show past and future trends for key climate change indicators (precipitation, temperature, wind speed, etc.) for Europe at a resolution of $50 \mathrm{~km} /$ pixel. It also contained higher level products based on these variables. For example, projections for 'growing season length' could be calculated from the number of consecutive days with temperature at $2 \mathrm{~m}$ height above ground surface level being greater than $5^{\circ} \mathrm{C}$. This could be plotted on a low resolution raster world map for periods of decades using single pixels to represent $50 \mathrm{x} 50 \mathrm{~km}$ squares. Both observed and modelled data was stored as data sets which could be retrieved via a Web portal to support climate change research and climate impact applications. From these data sets, maps and trend charts could be produced to visualise the data.

The principles discussed by Tett et al (2006) and Bernholdt et al (2005) for creating usable and acceptable systems were shared by the EuroClim project team. This was seen as important if the system being developed was to be successful with the potential user community.

The project partners responsible for processing satellite data to produce observed climate change variable data products were: the Norwegian Computing Center (project coordinator), Norwegian Meteorological Institute, Norwegian Polar Institute, Geological Survey of Denmark and Greenland, and the University of Cambridge, Department of Applied Mathematics and Theoretical Physics. The Max Planck Institute for Meteorology in Hamburg created the modelled climate data. NORUT Information Technology in Norway developed the IT infrastructure for the system. The Ergonomics and Safety Research Institute at Loughborough University (now part of the Loughborough Design School) was responsible for conducting the user requirements analysis for the system.

\section{Methodology}

\subsection{Incorporating user requirements analysis into the system design process}

While the EuroClim technical concept was established at the start of the project, it was planned to follow a user-centred design approach (ISO 9241, 2010) to guide the development of the system to ensure that it met user needs. Challenges faced in doing this were:

- Creating interest in the system concept and stimulating potential users to participate in requirements capture.

- Ensuring that users understood the system concept and appreciated how it could enhance their work.

- $\quad$ Obtaining a broad enough range of views to ensure that the system had wide applicability.

- Rapid and system development cycles which reduce the time available, between cycles, to organise and capture user feedback.

In order to address these problems, a flexible and iterative process was adopted. This involved the following steps: 
1. Produce a concept simulation of the system user interface based upon an understanding of its technical capabilities from project consortium meetings.

2. Develop a user survey to identify needs at a general level. This included screen images from the simulation showing potential system capabilities to stimulate comment and help generate requirements. The survey was conducted with groups of users with the results fed back to the project development team for consideration within the technical specification process.

3. A prototype EuroClim service portal was developed which could access data sets generated from satellite and modelled data via a web browser and website. Three versions of the prototype were produced and demonstrated in phased user panel sessions to obtain comments and suggestions.

4. The prototype was modified after each phase to reflect user feedback but keeping within the scope of the project.

This process is represented in Fig. 3:

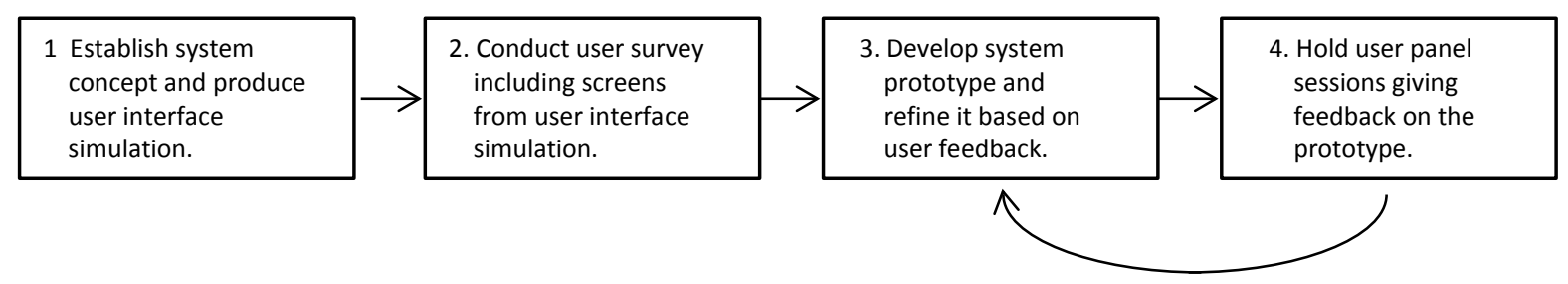

Fig. 3. General process for user needs capture

\subsection{User needs survey methodology}

An initial user requirements analysis for EuroClim was conducted in the first three months of the project. The EU as project sponsors required the system to be of benefit to a wide range of users and organisations across Europe. It was necessary then to gather the opinions of 'specialists' (scientists and climate change researchers) and 'non-specialists' such as professionals (applying climate change information for policy making, campaigning and dissemination), educationalists and members of the public (Maguire, 2002).

The criteria for inclusion in the survey for the specialists (e.g. scientists, researchers) were that climate change must be relevant to their work and that they must have a need for climate change information. The recruitment process involved drawing up a list of potential respondents. Many were known to the project partners but the majority of the recruitment was by making contacts with appropriate organisations (e.g. the UK Department for the Environment, The Environment Agency). For the nonspecialists, the main criterion for recruitment was that they had some need for climate-change information as part of their work e.g. teaching the topic to students or children. The members of the public who took part did not need to have a particular role relating to climate change but simply an interest in the topic.

In administering the survey, the project partners helped to distribute the survey to domain specialists in their field and across different countries. When required to overcome language barriers, they administered the survey face to face. The survey probed the respondent's background and interests in relation to climate change and potential needs for geographic climate data sets.

Two versions of the survey were developed, one for specialists and one for non-specialists to reflect their differing requirements of the system. Table 1 lists topics covered by each version. Most of the data collected were qualitative so the method of analysis was to assemble all the responses into a spreadsheet grouping them into the different user categories. A simple content analysis was then conducted on the textual data collected (Weber, 1990). The following steps were carried out:

1. All survey responses were grouped under particular user categories (scientists, professionals, educationalists, members of the public). The data for each group was then analysed separately.

2. All responses to each question (for each user group) were then reviewed and each distinct user requirement was identified and listed. 
3. User requirements in the list that were the same or similar were then noted as having added value since they were applicable to two or more users or organisations.

4. The requirements were then reviewed to see whether any could be related together to form a more general requirement, for example, 'sea ice concentration' and 'sea ice thickness' which are related and could be captured by a single sensor (satellite).

5. The requirements were also reviewed to see whether one was an extended or more specific version of another. For example, two organisations might have the same general need for 'rainfall data'. However one might request that this include the number of centimetres of rainfall over a given period and the number of days of rain during that period. This requirement could then potentially cover the needs of both organisations.

This process enabled a set of user requirements to be built up for input to the design process. Reliability was achieved by having a reasonably large number of responses (80) and clear survey questions meeting the research aim of determining user needs for climate change data. Validity was established by giving users the chance to respond to a wide range of climate data examples and including open questions to catch additional responses. By relating user responses to named organisations, this also helped to put the requirements into context.

Table 1. Two versions of survey structure and summary of questions

\begin{tabular}{|c|c|}
\hline Survey structure: Climate change specialists & Survey structure: Non-specialists \\
\hline $\begin{array}{l}\text { 1. Introduction } \\
\text { Description of the EuroClim system concept }\end{array}$ & $\begin{array}{l}\text { 1. Introduction } \\
\text { Description of the EuroClim system concept }\end{array}$ \\
\hline $\begin{array}{l}\text { 2. Background information from participant } \\
\text { Organisation, role, climate change interest. }\end{array}$ & $\begin{array}{l}\text { 2. Background information of participant } \\
\text { Profession or role (e.g. teacher), or if member of the } \\
\text { public. }\end{array}$ \\
\hline $\begin{array}{l}\text { 3. Observed cryospheric/climate variables } \\
\text { Needs for specific variables e.g. snow-on-land, sea ice, } \\
\text { glaciers. Data qualities required of each e.g. spatial } \\
\text { resolution, accuracy, frequency of update, preferred } \\
\text { units, how would like data set to be visualised. }\end{array}$ & $\begin{array}{l}\text { 3. Sources of climate change information used } \\
\text { Where respondent currently obtains information on the } \\
\text { topic and usefulness of particular sources. }\end{array}$ \\
\hline $\begin{array}{l}\text { 4. Climate model data } \\
\text { Needs for specific modelled variables: temperature, } \\
\text { rainfall, pressure, wind force, from climate model. } \\
\text { Comments on example displays of climate data and } \\
\text { task scenarios where climate data is needed. }\end{array}$ & $\begin{array}{l}\text { 4. Desirable features or information from system } \\
\text { Possible uses for EuroClim system e.g. how it would } \\
\text { help in teaching or what information would be most } \\
\text { interesting or useful. }\end{array}$ \\
\hline $\begin{array}{l}\text { 5. Statistical modelling } \\
\text { Relevance of statistical modelling capabilities within } \\
\text { EuroClim e.g. climate variable trends. How far climate } \\
\text { data needs to be projected (e.g. } 50 \text { or } 100 \text { years) and } \\
\text { how it should be visualised. }\end{array}$ & $\begin{array}{l}\text { 5. Comments on system structure/example displays } \\
\text { Comments on diagrammatic structure of information } \\
\text { and example displays presented of climate model data } \\
\text { e.g. future temperature, rainfall, wind force change for } \\
\text { a particular region. }\end{array}$ \\
\hline $\begin{array}{l}\text { 6. Additional comments } \\
\text { Potential benefit of EuroClim system to own role, } \\
\text { possible disadvantages and other comments. }\end{array}$ & $\begin{array}{l}\text { 6. Additional comments } \\
\text { Potential value of EuroClim system, how it should } \\
\text { work in general terms and other comments. }\end{array}$ \\
\hline
\end{tabular}

\subsection{User panel workshop methodology}

A barrier for user requirements elicitation is that it is difficult for users to know what they require from a system before they have experienced it (Robertson and Robertson, 1999).Therefore three sets of user panel sessions were organised in locations across Europe each covering one version of the EuroClim prototype. People from key organisations were recruited who used climate change related information as part of their role.

In recruiting for the panel sessions, project partner contacts within the climate change community were important for getting good representation from key organisations. Holding the sessions across several locations in Europe was needed to avoid participants incurring significant travel costs.

Each panel session was run over the course of a day with the following agenda:

- Welcome and introductions.

- EuroClim presentation including project objectives, conceptual description of system, description of different variable classes, demonstration of prototype, discussion. 
- Discussion about future needs for climate-change observation indicators and climate model variables.

- Hands-on exercise for participants with EuroClim prototype to perform tasks and view example data products followed by feedback, suggestions for change, potential role of system in scientific work, policy making, and information provision.

- Completion of participant feedback questionnaires on session.

Table 2 shows the chronology of the main stages of the user requirements elicitation process and prototype development. It shows the dates and location of each activity and number of participants involved at each stage.

The panel session notes for each prototype version of EuroClim were analysed together. Again a simple content analysis was applied. The panel discussions differed to a certain extent from the survey responses in that the panel members, on seeing the working prototype, tended to think more broadly about how it could be used within their organisation possibly for a new application area.

In analysing the panel discussion data, the following steps were performed:

1. Each distinct user requirement or possible application area for the system was identified and, where possible, the reasons for them (for example in the water industry, the frequency of drought conditions were important because services could cope with one very dry summer but had difficulties if there were two or more in a row).

2. These requirements and application ideas were listed and where there was clear agreement or overlap between suggestions, this was noted as potentially satisfying the needs of two or more organisations.

3. The requirements and ideas were also explored to identify any relationships between them that could form the basis for a new climate information service or extension to an existing service (for example, presenting the EuroClim data in a way that fitted the standard IPCC climate change scenarios).

This process helped to identify where the EuroClim prototype needed to be extended to match more precisely potential user needs and also where possible future application areas that had not been considered could be explored.

Panel members were also asked to give ratings of three aspects of the system: 'ease of use', 'usefulness' and 'potential impact' that it could have on climate change research and information provision. The trend of these ratings could then be monitored as the system developed.

Table 2. List of user requirements elicitation activities

\begin{tabular}{|l|l|c|}
\hline Dates/Location & Activity & Number of participants \\
\hline $\begin{array}{l}\text { October 2001- } \\
\text { February 2002 }\end{array}$ & User needs survey developed and conducted. \\
\hline $\begin{array}{l}\text { March to May 2004 } \\
\text { Oslo, Stockholm, } \\
\text { Vienna, London }\end{array}$ & $\begin{array}{l}\text { First round of user panel meetings/workshops. Aim } \\
\text { was to demonstrate and receive feedback from users } \\
\text { on Version 1 of the EuroClim prototype. }\end{array}$ & $\begin{array}{c}20 \\
\text { (4 meetings) }\end{array}$ \\
\hline $\begin{array}{l}\text { August - October 2004 } \\
\text { Zurich, Oslo, Bergen, }\end{array}$ & $\begin{array}{l}\text { Second round of user panel meetings/workshops to } \\
\text { Lemonstrate and receive feedback on Version 2 of the }\end{array}$ & $\begin{array}{c}\text { EuroClim prototype. } \\
\text { (4 meetings) }\end{array}$ \\
\hline $\begin{array}{l}\text { January 2005 } \\
\text { Oslo and Edinburgh }\end{array}$ & $\begin{array}{l}\text { Third round of user panel meetings/workshops to } \\
\text { demonstrate and receive feedback on Version 3 of the } \\
\text { EuroClim prototype. }\end{array}$ & $\begin{array}{c}21 \\
\text { (2 meetings) }\end{array}$ \\
\hline March 2005 & Completion of final version of the system. & \\
\hline
\end{tabular}




\section{Results}

\subsection{Survey results}

The survey (Maguire, 2002) elicited responses from 80 users. These included 42 scientists and researchers, 15 professional users (policy makers, members of governmental bodies and NGOs), 8 educationalists and 15 members of the public from a range of professions and backgrounds. The sample included representatives from over 50 organisations and 13 European countries. The main differences between participants from each country were the geographical area they were interested in. So, for example, people in the UK had a particular interest in observations of snow in Scotland while those in Switzerland were interested in snow cover, glacier change in the Swiss mountains and ice on Swiss lakes rather than sea ice in the Arctic Ocean.

\subsubsection{Scientists}

This user group was concerned with climate monitoring, climate modelling, and research into climate impact on human activity. They were based in specialised research institutes, government departments and university departments.

Climate monitoring scientists: Feedback was obtained from national meteorological services (e.g. the EUMETNET group), Arctic and Greenland surveys and commercial companies (e.g. Shell UK). Such services require weather data to look for trends, frequencies of extreme events (such as the 2003 European heat wave and the 2002 and 2010 floods) and correlations between indicators and different kinds of environmental data (e.g. the relationship between the weather and hydrological conditions in Greenland). They also look at comparing data sets for different countries and to build up historical data records for particular countries or regions. To support these needs, it was planned that EuroClim would provide variable data for temperature in the air and sea, precipitation, atmospheric pressure, wind speed and direction, relative humidity, runoff of fresh water from glaciers, ablation (removal of snow, ice, or water from a glacier or snow field), sea ice concentration, and sea ice thickness.

Climate modelling scientists: Climate modellers require observation data as starting values for running their own models and to compare with their own model predictions. EuroClim observed data could therefore support this requirement. Modellers also develop regional models as well as general models so having model data available for Europe was seen as useful. This group are also interested in a convenient way to compare their own model outputs with those of others, for example, the EuroClim model, in terms of accuracy (mirroring past observations) and future predictions.

Climate impact scientists: Climate impact scientists study the impact of climate change on particular activities such as construction, agriculture, tourism, shipping and water resources. In the survey, respondents were presented with a list of task scenarios relating to climate impact research. For example: 'An offshore planner wants to know the likelihood of a ship or off-shore platform encountering sea ice and high winds which could cause it damage'. Each user was asked to indicate what kind of data they would need to satisfy each scenario. The results summarised in Table 3 show how EuroClim data could be structured according to these scenarios or areas of study.

Table 3. Requirements for data to support specific usage scenarios for climate impact users

\begin{tabular}{|l|l|}
\hline Area of study & Climate change data required \\
\hline Effects on coastlines & $\bullet$ Sea level change \\
& • Sea level pressure \\
& • Wind speed for land and ocean \\
\hline Flooding and droughts & • Rainfall - levels and number of days of rain \\
& • Snow cover - depth and days of snow \\
\hline Avalanches & • Days of snow \\
& • Snow thickness \\
& • Wind speed \\
\hline
\end{tabular}




\begin{tabular}{|c|c|}
\hline Effect on agriculture & $\begin{array}{l}\text { - Temperature } \\
\text { - Rainfall - levels and number of days of rain } \\
\text { - Growing season length } \\
\text { - Frost, Soil moisture }\end{array}$ \\
\hline Effects on building industry & $\begin{array}{l}\text { - Land snow measures in Scandinavia } \\
\text { - Temperature, wind speed, rainfall }\end{array}$ \\
\hline Effects on skiing & - Snow cover - depth and days of snow \\
\hline Water resources & $\begin{array}{l}\text { - Rainfall - levels and number of days of rain } \\
\text { - Land snow in Scandinavia and Svalbard }\end{array}$ \\
\hline Ecosystems/biodiversity & $\begin{array}{l}\text { - Temperature } \\
\text { - Rainfall }\end{array}$ \\
\hline Socio-economic effects & - Historical change and trends in climate variables \\
\hline
\end{tabular}

Several participants wanted a general platform to provide data to support these different application areas as a 'one stop shop'. A further need was for data on extreme events (frequency and location) such as high winds, heavy rainfall and lack of rainfall. This would be useful for many sectors such as construction, infrastructure development and agriculture.

Survey respondents reported a number of problems experienced with climate observation data sets generally. These included: inconsistency between data from different sources, parameterisation not being specified, data calibration details not being provided, and products not being available in the required format. Rather than having them in the co-ordinates applied by the system, they wanted them as latitude-longitude so they could convert them into the geo-referencing system they required for their own analysis. They felt that there was insufficient metadata available for data sources such as: area covered, accuracy estimation, data calibration detail, dates and times of acquisition, how processed, projection or earth model used, and cloud fraction over region. There was also a desire for longer baselines of data (more than 30 years), for climate data to be provided more frequently (daily) and at a higher resolution (down to $5 \mathrm{~km}$ per pixel).

\subsubsection{Professionals}

The survey covered professional users with a range of interests including: natural hazards and extreme weather, agricultural practice and management, socio-economic effects of climate change, effects on ecology, species and habitat, needs of the building industry, and water and energy resource management. They often use information provided by climate impact scientists.

International organisations: A response was received from the European Environment Agency (EEA) who at the time was preparing a report on European climate change indicators for policy makers. Their interest was to disseminate information about EuroClim and promote it through their own portal. The United National Environment Programme (UNEP) has the role of worldwide environmental assessment, monitoring and management. They also provided programmatic support for the Rio Climate Change Convention, Conferences of the Parties (COP) to assess climate impact, response strategies and progress. UNEP were mostly interested in trends rather than individual data sets. They wanted climate model data with a resolution of $25 \mathrm{~km} /$ pixel rather than $50 \mathrm{~km} /$ pixel.

Ministries and Environment Agencies: This group employ climate data to help assist with national planning rather than to perform fundamental research. They use such data to look at correlations, for example, a water authority may look at runoff changes as a result of changes in temperature and precipitation. It was found that they might use climate change data to help with flood prevention and adaptation to climate change, to analyse the effects and prediction of extreme weather events in the certain regions, and for dissemination to citizens, teachers and professionals.

Conservation campaigners and NGOs (non-government organisations): Conservation users are concerned with particular aspects of nature conservation such as the countryside, plants, animal and bird species, while others are campaigners for environmental causes. They need meteorological data that is standardised, grid-based, readily available and validated for Europe and beyond. The provision of reliable trend information is important in helping them decide where future threats may come from. Comments by NGOs reflected that the fact their funding is spread thinly across activities so reasonable pricing of data products is needed. The main concern is that data needs to be validated and presented in a standard form across European countries. 


\subsubsection{Educationalists}

Teachers and lecturers responding to the survey were interested in being able to download data sets to support teaching activities, use in class and dissertation work. This could come from a database of climate variables, recorded on a daily basis giving students the flexibility to select multiple data sets and view and compare them. It was said that the system could provide study exercises and links to the corresponding data. An exercise might be, 'Is the trend for northern areas of Europe to be warmer and wetter or cooler and drier?' A function to show a time lapse map of climate variables was also thought useful to highlight possible changes taking place. These could be geographical views of the edge of an ice cap for different climate change scenarios or a comparison of climate model outputs with actual observation data. Also needed was a way to show whether the apparent changes are significant or part of natural variation. It was thought more important to provide an interactive system for students to test concepts and develop their understanding, rather than highly accurate data sets.

There was a need for higher level local maps or photos alongside the main data map so students could locate themselves geographically. Students often need guidance on interpreting maps so a commentary and conclusions about geographical data (maps, charts and graphs) would be useful if pitched at a suitable level for students.

\subsubsection{Members of the public}

In 2005, the UK's Department for Environment, Food and Rural Affairs (Defra) said "changing public awareness, attitudes and ultimately behaviour are all going to be vital if we are to achieve our climate change goals". Yet according to Nicholson-Cole (2005), for many people climate change seems like a remote problem and not one of personal concern. Lorenzoni et al (2007) observed, among members of the public who participated in their study, a general lack of confidence in interpreting scientific information and difficulty interpreting scientific uncertainty and complexity. This contrasts with scientists who are trained to recognise that uncertainty is an integral element of the process of discovery and debate. Moser (2007) warns that communication strategies aimed at increasing the sense of urgency to the public are often counterproductive. Some reports (for example, Jowit, 2010) have shown that a large proportion of public opinion is becoming sceptical about the threat of climate change. An important question is whether the provision of geographical information can promote public knowledge and engagement with the topic.

The EuroClim survey revealed the kinds of questions that public users would want to ask of a system: Is global warming happening? What are the causes? What are the effects going to be in my region, on people's living conditions, the climate generally, and on tourism and leisure activities?

They seemed to want a better understanding of climate change and related concepts such as global warming and the greenhouse effect. They were interested in the timescales of change, local effects, its likely severity, what actions governments and other organisations were taking, whether any actions they took would make a real difference.

It was said that climate change information via journals, newspapers and TV, sometimes suffered from problems of too much technical jargon, a lack of objectiveness, conflicting opinions, and an absence of regional or local information.

Desirable characteristics of a system for the public were for it to be accessible, easily understandable, avoiding complex terminology, and presenting an impartial point of view, making it believable and having a global influence especially on politicians. Public users also desired map-based, visual information and graphics to illustrate both the processes underlying climate change and the results of it. Donis (1974) states that people have greater expectations in receiving graphical, animated and interactive forms of information. It was suggested that it would be useful to see graphics or animations of the oceans showing ice margins, snow extent, and seasonal patterns to illustrate and compare 'warm' and 'cold' periods. Charts could show trends for the coming years and changes in regional climate.

It was thought that while the data sets within EuroClim would be interesting to have, people might have a problem understanding how the data has been aggregated and may assume, for example, that an upward graph indicates an increased numbers of days with gales or without rain every year. The system should present ranges of event frequency with upper and lower limits to show that each year will not necessarily contain extreme events. 


\subsection{User panel results}

This section describes the three rounds of user panel sessions and the main participant feedback from them.

\subsubsection{First round of user panels}

The first round of user panel sessions was based on EuroClim prototype Version 1. This contained a sample of climate and observation data sets that could be searched for and viewed. The sessions were held in four locations with participants from different organisations:

Oslo: $\quad$ European Environment Agency (EEA), Greenpeace, Center for International Climate and Energy Research-Oslo (CICERO), United Nations Environment Programme (UNEP/Grid Arendal), Aftenposten (Norwegian The Evening Post).

Stockholm: Naturvardsverket - Swedish Environment Agency.

Vienna: $\quad$ Umweltbundesamt - Austrian Environment Agency.

London: $\quad$ UK Environment Agency, UK Climate Impacts Programme.

Participants were generally enthusiastic about the EuroClim project. Although the prototype only had a few geographical data products available and some display formats needed refining, they could see its potential as a useful tool. They felt there was a need for more description or metadata for the products available which would help to make the system a credible and useful tool. The issue of data misuse was raised and a recommendation was made to provide guidance on data interpretation to help users avoid drawing the wrong conclusions from the data they downloaded.

While technical specialists (scientists and researchers) should be able to search for the data they need on the system, non-specialists might find it harder, so pre-defined results could be provided without needing to search, showing changes from observations in the Arctic and in the climate variables across Europe. Predefined graphs could convey basic messages to the public or provide a resource for those in an information dissemination role. As in the survey, it was said that specific guidance could be provided to activity sectors such as tourism, the building industry, insurance, shipping and farming, about which data products to view to highlight climate changes relevant to each one. It was planned that EuroClim would contain general climate indicators such as growing season length which could meet the needs of specific sectors.

\subsubsection{Second round of user panels}

Additional data products were added for EuroClim Version 2. Three panel sessions and one joint meeting with another research project were organised as follows:

Zurich: $\quad$ WWF International, EEA, Austrian Bureau for Climate Change.

Oslo: $\quad$ CICERO and Statistics Norway, UNEP/GRID-Arendal, Bellona Foundation (International environmental campaign oriented organization), Global Climate Observing System (GCOS)/World Meteorological Organization, Three representatives from education and the media.

Oslo: $\quad$ Meeting with representatives from the 'ICEMON project', implementing a European operational oceanography system for the high latitudes, consisting of sea ice, meteorological and oceanographic data.

London: Environment Agency, Department of the Environment, Food and Rural Affairs (Defra), University departments.

In the Zurich panel session with participants from Switzerland, Germany and Austria, there was strong interest in extending the monitoring area to cover Alpine glaciers and ice on Alpine lakes. Representatives from the Austrian and German Federal Environment Agencies were interested in phenological data, such as changes in the tree line in cold regions, and the overlap between climate and biological parameters (for example, snow cover and trees). This would require integration of climate data with data sets from forest monitoring. The EEA were interested in a broader range of products and covering more regions, for example, a map of water temperature changes for the Arctic Ocean showing both rising and sinking water, and Baltic Sea ice cover. This would feed into fact sheets they were developing for general dissemination.

In Oslo there was an expressed need from CICERO and Bellona (a Norwegian conservation and campaigning organisation) for assistance with climate change variables that were hard to monitor such 
as permafrost change, needed for IPCC negotiations. This is hard to monitor but related indicators that the system could import were forest fall and the volume of melt water. Bellona was interested in the melt speed of glaciers and sea ice as a climate change indicator in Northern Russia including changes in the Baltic and Kara seas.

The panel were particularly interested in products that showed the impact of climate variables such as sea ice, wave heights, number of freezing days and freezing dates, on the economy. They were also interested in parameters to help monitor carbon leakage, reforestation, and carbon storage, i.e. the 'Carbon Cycle balance'. This reflected, as in Zurich, a general interest in biological as well as physical indicators and the relationship between them.

Educational representatives in Oslo echoed the survey finding that the data sets could support teaching, stressing the need to provide good visualisation tools to show the dynamics of climate change and sea ice change to help maintain student interest. For example, ice movement could be shown allowing students to locate the position of 'The Pump' which is responsible for the flow of the Gulf Stream (and featured in the climate change movie 'The Day After Tomorrow'). As a result of this discussion, some general information and explanatory screens about climate change were added to the system for nonspecialist users.

In the meeting with ICEMON project representatives there was discussion about the use of sea ice concentration and snow cover data to create new climate change indicator products such as the number of days with sea ice per pixel and the first day of ice break-up. It was thought that both would be of interest to the shipping industry. Although the standard resolution for the monitoring of cryospheric data is $1 \mathrm{~km} /$ pixel, it was suggested that a more detailed resolution of $100 \mathrm{~m} /$ pixel would be a more useful basis for a shipping navigation service in the Northern Atlantic. In general the shipping industry requires higher resolution statistical data on sea ice concentration, temperatures, wind speeds, wave heights and long term trends to support design safety. There was also the potential for tailored services that shipping organisations might pay for including early warnings of high levels of sea ice concentration.

In London, it was said that anything that improves scenarios and confidence in climate change predictions is positive. Many people, not least national governments, simply want to know what is likely to happen in the future and so there is a need for clearer indications of the possible outcomes based upon climate models. If EuroClim products could improve the predictions from other organisations such as the Hadley Centre's climate model or the UK Climate Impacts Programme's climate change factors, this would be a benefit.

The representative from Defra wanted to be able to provide observation information to Government ministers to support policy development, presentations and speeches at EU and international meetings. The selection of information delivered influences its impact. For example, non-scientific users can relate to a statistic such as 'sea ice will disappear in summer in 50 years', more easily than 'the average temperature in Hampshire will rise by $1.5^{\circ} \mathrm{C}$ '.

Water industry representatives, reflecting the survey findings, were interested in observational data and predictions and frequency of extreme events, for example, of rainfall and temperature, and maximum and minimum values. It was said that water suppliers can cope with one dry summer by using the network to move water around but problems occur when there are several in a row. Monitoring ice and snow in other parts of Europe was also important for water supply. A warmer climate would mean that more water will fall as rain rather than snow causing reservoirs to overfill within a short space of time which could lead to disruption of water supplies and flooding.

Some participants wanted to be able to create their own climate change indicators based upon standard climate variables. The user could perhaps specify a threshold of interest, for example, the number of days when the temperature is over $30^{\circ} \mathrm{C}$, the length of time between occurrences of strong winds, or the number of days over a certain period without rain. This might form the basis for a commercial service where a user's query is received, the raw data are extracted from the EuroClim database, processed offline, and the results made available to user.

Regarding climate change prediction, 4 common scenarios are used by the IPCC (2001, 2007). These are: A2 - Low emissions scenario, A1 - Medium to low emissions scenario, B1 - Medium to high 
emission scenario and B2 - High emissions scenario. The middle scenarios (A1 and B1) represent the upper and lower bounds of probability and the outer scenarios, less likely outcomes. Long term predictions are also often classified within three time events: the 2050s, 2070s and 2090s. It was suggested that the modelled outcomes from EuroClim could be classified in the same way to fit in with the conventions adopted by the climate change community and organisations such as UKCIP and the IPCC.

\subsubsection{Third round of user panels}

Two third round panel sessions were held for EuroClim Version 3 which had a near complete set of examples of the different products. Organisations represented included:

- Oslo: Norwegian Pollution Control Authority (SFT), Department of GeoSciences - University of Oslo, UNU - Global Virtual University, UNEP/GRID - Arendal, WWF Norway Polar programme, AftenPost, and CICERO.

- Edinburgh: School of Geosciences, Geography Department (Edinburg University), National Data Centre at Edinburgh University (EDINA), and Scottish Environment Protection Agency.

The increasing number of products available made the system more interesting and participants could see more clearly its potential as a useful tool. The system provided data in HDF (Hierarchical Data Format) that technical specialists used but there was a need, especially for non-specialist users, for this also to be offered in more widely used formats such as Excel or CSV. It was thought that it should be possible to access some products quickly, for example, time series data for key variables that users can appreciate straightaway. Another suggestion was to be able to support side-by-side comparison of images and export data to combine with other data sets.

As previously discussed, in the educational field there is also a need for graphical and dynamic presentations that students can view and interact with. However the ability to download data sets could form the basis of more advanced case study work.

\subsubsection{User ratings and system changes}

The participants within each session were asked to rate the ease of use of the prototype EuroClim system, on a five point scale: 'very difficult', 'difficult, 'neutral', easy' and 'very easy' reflecting the fact that they can experience different levels of either ease or difficulty when using the system.

They also rated their perceived usefulness of the system and its potential impact within the climate change community on four point scales: 'not useful', 'slightly useful', 'useful', or 'very useful', and 'no impact', 'slight impact', 'significant impact' or 'great impact'. This is because the concepts of usefulness and impact do not implicitly contain a balanced scale of positivity and negativity but rather range from 'not useful'/‘no impact' to 'very useful'/‘high impact'.

The average ratings from each round of user panel sessions are shown in Table 4.

Table 4. Mean participant ratings of EuroClim from panel sessions

\begin{tabular}{|l|c|c|c|}
\hline & Prototype v1 & Prototype v2 & Prototype v3 \\
\hline $\begin{array}{l}\text { Ease of use } \\
\text { (scale 1 to 5) }\end{array}$ & 2.6 & 3.1 & 3.2 \\
\hline $\begin{array}{l}\text { Usefulness } \\
\text { (scale 1 to 4) }\end{array}$ & 2.4 & 3 & 3.3 \\
\hline $\begin{array}{l}\text { Impact } \\
\text { (scale 1 to 4) }\end{array}$ & 2.7 & 2.5 & 3.5 \\
\hline
\end{tabular}

It can be seen that the average ratings tended to increase as the prototype system and climate data products developed.

Problems of ease of use at the user interface level were perhaps relatively straightforward to correct early on and so the improvements were reflected in the more significantly improved ratings of ease of use and usefulness from Version 1 of the prototype to Version 2. In terms of usefulness, the feedback from the user panels helped firm up the ways in which data products should be presented, combined and downloaded. For land snow, for example, a user could choose between the primary products, snow 
cover area, surface temperature of snow and snow surface wetness and indicator products, number of snow days, total snow area, days of snowmelt and total snow met area. The user could also choose a quality threshold, a time interval and aggregation period (month, season or year) for the product of interest. Downloaded products could be added to a collection and then each viewed for all months in the specified year or the same month for a series of years. For single raster products, for example, glacier melt area, the user could choose to display the average, maximum or minimum area. For multiple products they could switch manually between them to detect differences, or view them as an animated sequence. All these aspects helped make the system portal outputs more useful. As the full range of products were available to explore, this probably contributed to the improved impact ratings from Version 2 to Version 3.

\section{Discussion: communicating climate change with graphics}

Conducting the user survey and user panel sessions on the Euroclim project highlighted a number of general themes in relation to helping users appreciate and understand geographical information in relation to climate change. These are discussed below:

\subsection{Engagement and ease of understanding}

It was clear from the project survey and panel sessions that the use of graphics to receive climate change information was important for all user groups. In the study, the use of trend charts, comparison charts and dynamic information were suggested as ways to help make the information more engaging and easier to consume. This is particularly true for non-specialists such as policy makers or educationalists who need access to climate change information but have a limited time to process it. For casual users with a passing interest in the topic, possibly while reading a newspaper, visiting a museum exhibition or helping a child with homework, it is also important to capture their attention in a short space of time. Graphical information must therefore be easy to assimilate and understand. It was revealing that a scientific journalist, attending one panel session, stated that his main requirement was for maps or charts to supplement climate change articles he was writing.

Time series maps, often presented as animations are effective at showing how a climatic variable or feature will change over time. They can show how a region, for example, the Arctic Ocean, may experience reducing sea ice in the future possibly leading to ice free summers. However a dynamic display only gives the viewer a general impression of what is happening. Having an interactive feature for users to plot and compare a climate variable for specified locations over time would help to supplement an animation and make it clearer.

New ways to present climate change data can stimulate people's imaginations and give greater insight into the subject. A map produced by Météo-France (2011) displays various European cities displaced to new locations to show the projected climate they can expect in the future. For example, using a calculated projection, London in 2071 could have a climate closely matching that of the west coast of Portugal as it is today. See a reconstructed section of the map below (Fig. 4).

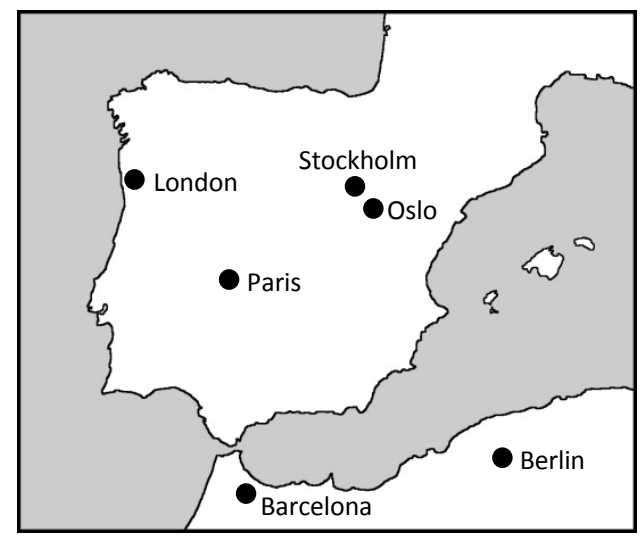

Fig. 4. Map illustrating how temperatures of European cities may change by 2071 by relocating them to locations with a similar climate today 
Some climate change maps try to communicate the effect of an average rise in temperature of $1-4^{\circ} \mathrm{C}$ on different places in the world. While this rise may seem small it is just an average rise and more extreme temperature changes may take place in different parts of the world. Global effects may be varied and complex making the whole picture seem fragmented. To highlight the ideas and impacts more clearly, an interactive world map was developed by the Met Office Hadley Centre and Science Museum (2009). This allowed users to select a category such as forest fires, crops, water availability, and a location, to obtain information on future environmental changes in that locality.

Sheppard et al (2005a), Nicholson-Cole (2005) and Shaw et al (2009) have argued that landscape visualisation of recognisable places may have special advantages in the communication of useful information and engaging emotions that may be necessary to motivate action on climate change. Using 2D and 3D geographical representations of a local region (Delta in SW British Columbia, Canada) these researchers have been able to show the potential effects of climate change such as sea level rise and increased storms, and the results of possible scenarios of local action. These include: controlling the location and density of population development, promotion of walking and alternative transport, encouraging energy conservation and fuel switching.

It is believed that visualisation based on dynamic elements and interactivity are attractive to lay-people and can help to close the gap between global climate change and local impacts and action, while following ethical guidelines for using emotionally charged imagery (Sheppard, 2005b). Conceptual requirements for producing visualisation systems to inform and motivate lay-people, planners, and policy makers about climate change are given by Sheppard et al (2011). Sheppard et al (2008) also suggest that to bring climate change into people's backyards requires three things: 'disclosure' provide a personal and meaningful window into the future; 'drama' - a vivid and compelling presentation; and 'defensibility' - a systematic and credible process that enables transparency and trust in the presenters and the underlying information.

Presenting ideas on a large scale can also create impact. The Science Museum's Exploring Space hall includes a large sphere on which images are projected to create a revolving Earth showing world-wide movements of ocean currents, weather events, the seasons and other features including night time electric light illumination and air traffic over a 24 h period (see Fig. 5). This form or dynamic realistic display could be the basis for an educational facility to present facts and ideas about climate change, possible future scenarios and the potential effects in different parts of the world.
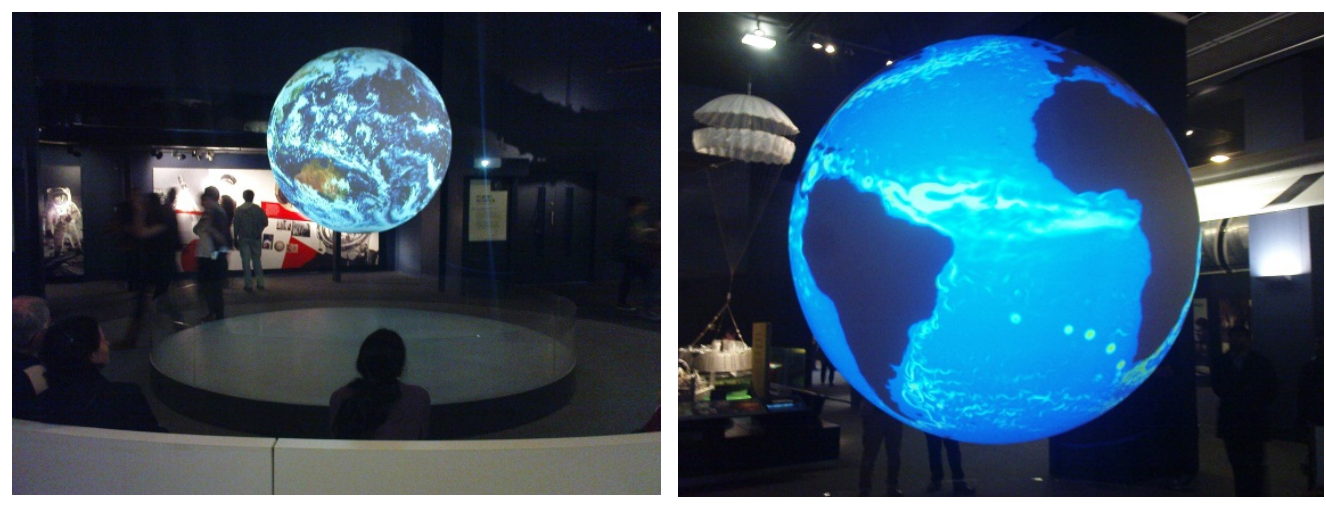

Fig. 5. Large Earth globe created by image projection in the London Science Museum

\subsection{Location, orientation and titling}

Graphical information products occasionally lack adequate titling, labelling of axes and legends causing confusion for the user. This can be due to the limited space in which a map is displayed making understanding by the casual user more difficult. Techniques such as presenting the name of the region (for example 'North Greenland'), showing lines of longitude and latitude, and the inclusion a small inset map of a larger area, can overcome these problems. A facility to zoom out from, or to pan across, a map to see the wider context is also helpful. Displaying the north direction with an arrow is the conventional way for a user to orientate themselves on a map, while an interactive feature to automatically rotate to north would also be useful. In the panel sessions some participants wanted the map to display what projection was used for transforming the spherical coordinates (latitude and 
longitude) into an XY (planar) coordinate system, for example, UTM (Universal Transverse Mercator) projection or Massachusetts State Plane projection. Basic guidance on map design is provided by Brewer (2005) and Krygier and Wood (2011).

\subsection{Technical language and climate change concepts}

As with every scientific community, climate change monitoring has its own technical terms or jargon so their use without explanation can present a barrier as was reported in the EuroClim user survey. Examples are: 'cryosphere' - the areas on earth where ice and snow predominate, 'albedo' - the reflecting power of a surface such as snow, and 'radar backscatter' - the way surface features exhibit different scattering characteristics detected by a satellite. Such terms, if presented with a graphical image need to be explained so that non-technical users can better understand the information being presented. This follows Nielsen's (1994) usability heuristic: 'Match between system and the real world' which says that "The system should speak the users' language, with words, phrases and concepts familiar to the user, rather than system-oriented terms".

Values such as average precipitation (rainfall) or temperature are meaningful to most people. However the use of more statistical forms of data presentation such as a 'running mean', used to smooth out short term fluctuations in data, will be less so. The survey also highlighted the need to communicate basic concepts to non-specialists such as the difference between 'weather' (the state of the atmosphere at a given time and place) and 'climate' (average weather conditions over a long period and a wide area). Explanations may also need to be given to distinguish between the 'projection' of climate variables (conditional prediction about the future depending on a certain set of circumstances) and their 'prediction' (an attempt to produce the most likely description or estimate of the actual evolution of the climate in the future).

Climate change models give approximations of change for relatively large areas, typically $100 \times 100$ or 50 x 50 kilometre squares although models can be generated based on higher or lower resolutions of data (Mitchell et al, 2004; Russell, 2010). Thus it is difficult to model how the climate would change specifically for a particular town or city in the future. If a projected mean temperature is shown for a particular area, a town or city within that area may experience a different average temperature to the whole area perhaps due to it being more exposed or sheltered, higher up or lower down, on the coast or inland. These concepts are important to communicate to non-professionals so they are not misled by climate change data sets that they might access. Systems such as EuroClim thus need to communicate this 'broad brush' nature of climate change information.

\subsection{Background information and interpretation support}

Climate change information can only be usefully employed if the user has some knowledge of its accuracy and reliability. In the view of several scientists in the EuroClim survey, there was often insufficient background information or metadata provided by climate change database systems to help them interpret climate change data sets and apply them appropriately. The ISO standard 19115 (2003) for metadata, assists in providing a framework for data providers to include the required background information and in a standard form. However for non-specialists such as professionals or teachers who might wish to use climate change data, there might be a need for simplified metadata that makes the most important background information accessible to them. Some users in the survey, especially members of the public, wanted information about the significance of the data displays that they were looking at. This needs to be presented in an understandable and unbiased way, giving a factual explanation of the data being displayed and possibly describing the implications for people living in that area.

\subsection{Standards and conventions}

The application of GIS standards and conventions in the design of a system provides consistency allowing users to build up and apply knowledge and experience from previous systems they have used (Nielson, 1994). Standards and conventions also embody good design practice helping the system to be user friendly. Website design conventions argued for by Nielsen (2004) such as: having a search box on the home page, navigation links in a left-hand menu or on tabs across the top of the screen, a shopping trolley link (for obtaining GIS products) in the upper right corner, also provide familiarity to users. Good practice design guidelines for GIS are provided by Heywood et al (2006) and Longley et al (2011). 
Use of colour is also important. Colours on maps should try to reflect human stereotypes for interpretation and avoid conflicting with them. If, for example, a graphical image for snow cover used warm colours (yellow, orange or red) to show increasing depth, this tends to conflict with the nature of the feature it represents. Use of such colours to indicate climate warming, with blue and purple to show cooling, better fits human cognitive stereotypes. Good examples are the displays and animations representing climate change produced by the National Aeronautics and Space Administration (NASA), United Nations Organization for Education, Science and Culture (UNESCO), the UK Meteorological Office (Met Office) and the British Broadcasting Corporation (BBC).

When presenting scientific information, the established scientific and professional ethic is to achieve honest and accurate visualisations with high standards of defensibility. When dynamic visualisation techniques are used this may be sensitive for people directly affected and may elicit emotional reactions. Sheppard et al (2008) advocates the development of a code of ethics based on the following principles:

- Accuracy of visualisation relative to expected conditions.

- Representativeness of geographical views in space and time relative to the context.

- Visual clarity of presentations.

- Interest and engagement of the audience or users.

- Legitimacy or accountability of the visualisations, including transparency of data and the production process.

- Accessibility of the visualisations to the public and potential users.

\subsection{Data integration}

The EuroClim survey and panel sessions generated the user requirement to be able to integrate climate data with other information such as bio-geographical or social data. In order to support this, climate products must be well documented using metadata and be available in universal formats such as ACSII or Excel for easier use by non-specialists and conversion to other formats. Provision of data in latitude/longitude was also seen as helpful in allowing users to match climate data with other data sets.

\section{Conclusions}

This paper has reported on the results of user requirements elicitation for the EuroClim climate change monitoring system and has identified strategies for the effective communication of climate change information with images.

The use of a survey to gather information from a wider group of people at a general level, and the organisation of panel sessions for potential users to interact with a prototype and discuss the system in more detail, was useful and complimentary with the panel findings helping to reiterate many of the survey results.

The panel meetings were productive and demonstrations of the system were generally well received. One challenge, with a constantly evolving system connected to an online database, was to create demonstrator prototypes robust enough for people to explore freely. To address this, a number of products were downloaded that users could refer to. They were also given an interaction script to follow, that was known to work for the system, before exploring freely themselves.

The project provides a case study of how ergonomic methods may be adapted for a particular application area (as described by MacLeod, 2003) and demonstrates how an early focus on the requirements of a diverse user community can help to clarify requirements for new technological developments, as shown by Martin et al (2012).

Some general climate data themes from the user requirements emerged: (i) the need for full coverage of snow and ice regions, (ii) an ability to integrate climate change data with biological or other variables, (iii) availability of comprehensive metadata, (iv) calculating projections of extreme as well as average events, and (v) for modelled data to fit in with IPCC (Intergovernmental Panel on Climate Change) scenarios.

Many non-specialists wanted pre-prepared data such as fact sheets indicating climate change possibilities that could aid activities such as policy discussions. For education, it was felt that data 
products from the system could support teaching activities especially if supplemented with background information and suggestions for student exercises. There was also a need for interactive presentations that students could view and explore. Climate change data sets could form the basis for case study work while the ability to compare downloaded products, including exercise questions, would offer further learning opportunities.

One of the main challenges in creating a system to meet the needs of both specialist and non-specialist users is to create flexible products supported with enough information to be usable by both groups. It is desirable to have an objective commentary of what each climate data product is showing and its implications for climate change.

The study found that there was a public desire for introductory information about climate change and the ability to access data that is both neutral and easy to understand. It is important to represent the levels of uncertainty relating to the data presented. A starting point to stimulate interest may be to make the information personal i.e. 'how future climate change may affect you in your own region and what can you personally do to help’.

The study has identified some general aspects of graphical climate change information that are important to all users: the need for climate change images to be easy to understand possibly with innovative formats. Also helpful are clear location, orientation and titling information, explanations of technical language and concepts, provision of background information and interpretation support. Dynamic and interactive displays help considerably in promoting user engagement with the information being presented. Supporting these needs will ensure that systems providing geographical climate change information are effective in the future.

\section{Acknowledgement}

The author would like to acknowledge the support of the EU IST (Information Society Technologies) programme in funding EuroClim and the productive collaboration with the project partners. Further information is available at http://www.euroclim.net

\section{References}

Amos J., Cryosat Spots Arctic Sea-ice Loss in Autumn, 2013, BBC News, 13 February 2013 http://www.bbc.co.uk/news/science-environment-21437680, (accessed April 2013).

Bernholdt D., Bharathi S., Brown D., Chanchio K., Chen M., Chervenak A., Cinquini L., Drach B., Foster I., Fox P., Garcia J., Kesselman C., Markel R., Middleton D., Nefedova V., Pouchard L., Shoshani A., Sim A., Strand G. and Williams D., The earth system grid: supporting the next generation of climate modelling research, Proc. IEEE 93 (3), 2005, 485-495, March 2005.

Brewer C.A., Designing Better Maps: a Guide for GIS Users, 2005, ESRI Press; Redlands, CA, 220.

Chapman J., Age of 100 Degree Summers, 2002, Daily Mail, 28-29, Friday 26 April 2002.

Donis D.A., A Primer of Visual Literacy, 1974, The MIT Press; Cambridge, MA.

Gould J.D., Boies S.J. and Lewis C., Making usable, useful, productivity-enhancing computer applications, Commun. ACM 34 (1), 1991, 74-85.

Heywood I., Cornelius S. and Carver S., An Introduction to Geographical Information Systems, 2006, Pearson Education Limited; Harlow, Essex, UK.

IPCC, Climate Change 2001, Third Assessment Report, Intergovernmental Panel on Climate Change (IPCC), 2001, Cambridge University Press; UK.

IPCC, Climate Change 2007, Fourth Assessment Report, Intergovernmental Panel on Climate Change (IPCC), 2007, Cambridge University Press; UK.

ISO 19115, Geographic Information - Metadata (corrigendum 1), Expected to Be Replaced by Part 1 Covering Base Metadata and Part 2 Including Extended Elements for the Description of Imagery, 
Gridded Data and Data Collected Using Instruments, 2003, International Organization for Standardization; Geneva.

ISO 9241-210, Ergonomics of Human-system Interaction - Part 210: Human-centred Design for Interactive Systems, 2010, International Organization for Standardization; Geneva.

Jowit J., Sharp Decline in Public's Belief in Climate Threat, British Poll Reveals, 2010, The Guardian, Wednesday 24 February 2010, p9 and online, Tuesday 23 February 2010

http://www.guardian.co.uk/environment/2010/feb/23/british-public-belief-climate-poll/, (accessed April 2013).

Krygier J. and Wood D., Making Maps: a Visual Guide to Map Design for GIS, second ed., 2011, The Guildford Press, Guildford Publications; New York, 256.

Longley P.A., Goodchild M.F., Maguire D.J. and Rhind D.W., Geographic Information Systems and Science, 2011, John Wiley \& Sons Inc.; Hoboken, New Jersey.

Lorenzonia I., Nicholson-Cole S. and Whitmarsh L., Barriers perceived to engaging with climate change among the UK public and their policy implications, Glob. Environ. Change 17, 2007, 445-459, August-October 2007.

Météo-France, The climate map of Europe 2071, Photograph: Centre International de Recherche sur l'Environnement et le Développement and Ecole Nationale de la Météorologie, Météo-France, 2011 guardian.co.uk http://environment.guardian.co.uk/flash/page/0,,2079347,00.html, (accessed April 2013).

MacLeod I.S., Real-world effectiveness of ergonomic methods, Appl. Ergon. 34(5), 2003, 465-477.

Maguire M.C., Deliverable 1-User Requirements Report, EuroClim IST-2000-28766 Project, ESRI (Ergonomics and Safety Research Institute) - Now Part of Loughborough Design School, 2002, Loughborough University; UK, 12 February 2002. Copy available from the author.

Maguire M.C., The use of focus groups for user requirements analysis, (Chapter 5). In: Langford J. and McDonagh D., (Eds.), Focus Groups - Supporting Effective Product Development, 2003, Taylor and Francis; London.

Martin J.L., Clark D.J., Morgan S.P., Crowe J.A. and Murphy E., A user-centred approach to requirements elicitation in medical device development: a case study from an industry perspective, Appl. Ergon. 43(1), 2012, 184-190.

Met Office Hadley Centre and Science Museum, Climate Map Shows World after 4C Rise, 2009 guardian.co.uk http://www.guardian.co.uk/environment/2009/oct/22/science-museum-climate-map/, (accessed April 2013).

Mitchell T.D., Carter T.R., Jones P.D., Hulme M. and New M., A Comprehensive Set of Highresolution Grids of Monthly Climate for Europe and the Globe: the Observed Record (1901-2000) and 16 Scenarios (2001-2100), 2004, Tyndall Centre for Climate Change Research, Working Paper 55, July 2004 http://www.tyndall.ac.uk/sites/default/files/wp55.pdf, (accessed April 2013).

Moser S.C., More bad news: the risk of neglecting emotional responses to climate change information, In: Moser S.C. and Dilling L., (Eds.), Creating a Climate for Change: Communicating Climate Change and Facilitating Social Change, 2007, Cambridge University Press; New York, USA, 64-80.

Mukherjee S., Prince's Plea over Climate Change, BBC Radio 4 Today Programme, 2005, 27 October 2005 http://news.bbc.co.uk/1/hi/uk/4380658.stm, (accessed April 2013).

Nielsen J., Heuristic evaluation, In: Nielsen J. and Mack R.L., (Eds.), Usability Inspection Methods, 1994, John Wiley \& Sons; New York, NY. Also available at: http://www.nngroup.com/articles/tenusability-heuristics/, (accessed April 2013). 
Nielsen J., The Need for Web Design Standards, 2004 http://www.nngroup.com/articles/the-need-forweb-design-standards/, (accessed April 2013).

Nicholson-Cole S., Representing climate change futures: a critique on the use of images for visual communication, Comput. Environ. Urban Syst. 29(3), 2005, 255-273, May 2005.

Robertson S. and Robertson J., Mastering the Requirements Process, 1999, Addison-Wesley Longman; Harlow, UK.

Robson C., Real World Research, third ed., Chapter 10 - Surveys and Questionnaires. Chapter 11Interviews and Focus Groups 2011, John Wiley \& Sons Ltd; Chichester, West Sussex, UK.

Russell R., Resolution of Climate Models, 2010, University Corporation for Atmospheric Research (UCAR), Office of Education and Outreach, 29 November 2010

http://eo.ucar.edu/staff/rrussell/climate/modeling/climate_model_resolution.html, (accessed April 2013).

Shaw A., Sheppard S.R.J., Burch S., Flanders D., Wiek A., Carmichael J., Robinson J. and Cohen S., Making local futures tangible - synthesizing, downscaling, and visualizing climate change scenarios for participatory capacity building, Glob. Environ. Change 19(4), 2009, 447-463, October 2009.

Sheppard S.R.J., Landscape visualisation and climate change: the potential for influencing perceptions and behaviour, Environ. Sci. Policy 8(6), 2005a, 637-654, December 2005.

Sheppard S.R.J., Validity, reliability, and ethics in visualization, In: Bishop I. and Lange E., (Eds.), Visualization in Landscape and Environmental Planning: Technology and Applications, 2005b, Taylor and Francis; London, 79-97, (Chapter 5).

Sheppard S.R.J., Shaw A., Flanders D. and Burch S., Can visualization save the world? Lessons for Landscape Architects from visualizing local climate change, In: Conference Proceedings, 9th International Conference on Digital Design in Landscape Architecture, 2008, Anhalt University of Applied Sciences, Dessau/Bernberg/Köthen, Germany.

Sheppard S.R.J., Shaw A., Flanders D., Burch S., Wiek A., Carmichael J., Robinson J. and Cohen S., Future visioning of local climate change: a framework for community engagement and planning with scenarios and visualisation, Futures 43(4), 2011, 400-412.

Solberg R., EuroClim: monitoring the cryosphere to improve climate change modelling, In: 3rd EARSeL LIS SIG Workshop, March 11-13, Bern, Switzerland, 2002 http://publ.nr.no/3556, (accessed April 2013).

Solberg R., A new system for climate change monitoring in the cryosphere, In: 31st International Symposium on Remote Sensing of the Environment (ISRSE), June 20-24. Saint Petersburg, Russia, 2005 http://publ.nr.no/4471, (accessed April 2013).

Taylor B., The HUFIT planning, analysis and specification toolset, In: Diaper D., Cockton G., Gilmore D. and Shackel B., (Eds.), Human-computer Interaction - INTERACT '90, Amsterdam, 1990, 371-376.

Tett S., Bates J., Boers R., Chédin A., Dewitte S., McCarthy M., Schulz J. and Thomas W., Position Paper - Post-EPS: Generic Requirements on Climate Monitoring, 2006, 7 March 2006 http://www.eumetsat.int/groups/pps/documents/document/pdf_peps_pp_climate.pdf, (accessed April 2013).

Weber R.P., Basic Content Analysis, second ed., 1990, Sage; Newbury Park, CA. 